\section{Eye-blink elicitation and measurement in the human infant: A circuit modification}

\author{
ROGER R. MARSH \\ Children's Hospital of Philadelphia \\ Philadelphia, Pennsyluania 19104 \\ and \\ HOWARD S. HOFFMAN \\ Bryn Mawr College, Bryn Mawr, Pennsylvania 19010
}

Marsh, Hoffman, and Stitt (1979) described an electromechanical device that elicits a reflexive eye blink in human infants by employing a miniature solenoid to deliver a controlled tap to the glabella (the patch of flattened skin between the eyebrows). An optical device for measurement of the eye blink was described also. This unit illuminates the eye with infrared light that is modulated at $5 \mathrm{kHz}$. The detector circuit reads the light reflected from the eye (or eyelid) and filters out signals below $5 \mathrm{kHz}$ so as to reject spurious signals resulting from fluctuating ambient light levels. As Marsh et al. noted, this circuit is somewhat susceptible to voltage transients, and hence one must use appropriate shielding if recording artifacts are to be avoided. In practice, this problem can sometimes be troublesome because of the many potential sources of electrical transients in most laboratory settings. This report describes a single circuit modification that completely and permanently corrects the problem.

The detector's response to voltage transients is due to the rectifier stage described in Figure 5 of the paper by Marsh et al. (1979). In that figure, the 741 op-amp charges a .68 -microF capacitor via a 1 N4148 diode. The op-amp is exquisitely sensitive to radio-frequency power-line transients, and because of its low output impedance, it quickly charges the capacitor as it propagates these transients. The correction is to cut the connection between the diode and capacitor and insert a $2.2-\mathrm{kohm}$ resistor. With this change, the capacitor charging-time constant is still short enough that the detector faithfully follows variations in the $5 \mathrm{kHz}$ carrier; but it is now long enough to make the circuit insensitive to brief transients.

\section{REFERENCE}

Marsh, R. R., Hoffman, H. S., \& Stitt, C. L. Eye blink elicitation and measurement in the human infant. Behavior Research Methods \& Instrumentation, 1979, 11, 498-502.

(Received for publication July 7, 1981; accepted July 28,1981 .) 